\title{
QUEIXA ESCOLAR: ATUAÇÃO DO PSICÓLOGO E INTERFACES COM A EDUCAÇÃO'
}

\author{
Sabrina Gasparetti Braga² \\ Maria de Lima Salum e Morais ${ }^{3}$
}

Resumo: Pretende-se com este trabalho discutir se as recentes políticas educacionais e de saúde e se os estudos a respeito da demanda escolar em clínicas-escola e em serviços públicos de saúde têm surtido efeito e provocado mudanças significativas na prática dos psicólogos das Unidades Básicas de Saúde (UBSs). Uma análise dos prontuários de crianças que demandaram, no segundo trimestre de 2005, a área de saúde mental de UBSs da região norte do município de São Paulo revelou que a queixa escolar surgiu em porcentagem significativa dos casos, indicando uma tendência das escolas a considerar que as dificuldades de ajustamento escolar são causadas por fatores centrados na criança e em sua família, em detrimento da implicação de questões educacionais, socioculturais e econômicas. Verificouse, ainda, que a conduta adotada pelos psicólogos, calcada no modelo clínico tradicional, tende a reafirmar essa crença, excluindo o papel da instituição escolar na produção e solução das dificuldades apresentadas. Propõe-se um repensar das práticas dos profissionais que atuam na rede pública de saúde e educação no sentido de procurar novas formas de atender à queixa escolar, levando em conta todos os fatores nela implicados.

Palavras-chave: Ajustamento escolar. Serviços de saúde mental. Atuação do psicólogo.

Diversos trabalhos a respeito do atendimento psicológico a escolares na rede pública de saúde e em clínicas-escola têm mostrado que a maior parte da demanda encaminhada traz queixas relativas à inadaptação à escola e a dificuldades de

1 Este artigo foi elaborado a partir dos resultados de um estudo realizado para conclusão do Programa de Aprimoramento Profissional em Saúde Coletiva, financiado pela Secretaria Estadual da Saúde (São Paulo, SP), por meio da FUNDAP.

2 Instituto de Saúde - Secretaria Estadual da Saúde ( São Paulo, SP). E-mail: sabrinagasparetti@hotmail.com

3 Doutora em Psicologia, pesquisadora do Instituto de Saúde, Secretaria Estadual da Saúde (São Paulo, SP). E-mail: salum@isaude.sp.gov.br

PSICOL. USP, São Paulo, out./dez. 2007, 18(4), 35-51 
aprendizagem (Bueno, Morais, \& Urbinatti, 2001; Carvalho \& Térzis, 1989; Nutti, 2000; Santos, 1990; Silva, 1994; Souza, 1997). Embora o resultado de tais estudos tenha apontado para a importância de identificar questões que extrapolam a dinâmica individual e familiar dos queixosos, persiste uma tendência, tanto por parte dos profissionais da educação quanto dos da saúde, a tratar os problemas de adaptação à escola como de origem exclusivamente biológica ou psicológica.

De acordo com Collares e Moysés (1986), existe atualmente uma patologização do processo ensino-aprendizagem. Buscam-se soluções médicas para problemas eminentemente sociais, o que se reflete numa tendência à medicalização e à psicologização dos problemas escolares, que são encaminhados para as Unidades Básicas de Saúde numa busca de resolução, já que as causas dos problemas de rendimento escolar são atribuídas aos pais ou à própria criança. Tais ações acabam por culpabilizar apenas o aluno pelo seu "fracasso",isolando-o do sistema público de educação, que também contribui para a criação e a manutenção do problema.

Segundo essa forma de abordar problemas de ajustamento à escola, dificuldades de aprendizagem e problemas de comportamento surgem em decorrência de conflitos vividos internamente pela criança, como conseqüência da pobreza, de uma família desestruturada ou de carência afetiva. Esse conjunto de interpretações não considera o que se passa na escola, revelando uma tendência a avaliar que os desajustes escolares são causados por fatores orgânicos e psíquicos da criança, em detrimento da implicação de questões educacionais, sociais, culturais e econômicas.

Muitos psicólogos ainda encampam essa forma de abordar a questão da queixa escolar. Dimenstein, discutindo a formação em psicologia, levanta a problemática de se adotar um modelo hegemônico de subjetividade nesse campo, que propõe um "sujeito psicológico", desenvolvido a partir do ideário individualista:"um indivíduo autônomo, senhor de si e independente, ou seja, ausente de vínculos e dos determinismos universalmente definidos pela cultura, que marcam a ideologia ocidental moderna" (Dimenstein, 2000, p. 96).

Breve histórico da psicologia e das equipes de Saúde Mental nas Unidades Básicas de Saúde da cidade de São Paulo

A inserção do psicólogo em equipes de atenção primária no município de São Paulo ocorreu a partir de 1981.Em 1985, com a reforma sanitária e psiquiátrica, alguns psiquiatras passaram também a integrar esses serviços (Morais, informação verbal, setembro de 2006). O governo do município de São Paulo, no período de 1989 a 1992 - além de reforçar as equipes de saúde mental nas Unidades Básicas de Saúde com a contratação de maior número de psicólogos, psiquiatras e a inclusão de 
terapeutas ocupacionais -, assumiu o compromisso de propiciar novas modalidades de atendimento em saúde mental, tais como hospitaisdia, centros de convivência, atendimento de emergências psiquiátricas em prontos-socorros e equipes de saúde mental em hospital-geral (Lopes, 1999).

É importante citar algumas das diretrizes adotadas na implantação desse novo modelo de atenção à saúde mental, como a valorização do perfil epidemiológico e social da realidade territorial-local, da transdisciplinaridade e das ações intersetoriais. Além disso, salienta-se a importância das crenças populares locais com relação ao enfrentamento de problemas de saúde, da determinação social do sofrimento mental, da subjetividade do sofrimento psicossomático, da produção do fracasso escolar, de uma atitude não-laudatória (que sustenta o surgimento de classes especiais nas escolas públicas), do investimento e reconhecimento do vínculo como via terapêutica e da sensibilidade na escuta (Lopes, 1999).

Destaca-se o investimento em educação popular, que ocorria paralelamente à qualificação dos profissionais de saúde mental, mudando-se a perspectiva de saúde como simples ausência de doença e ampliandose as respostas aos problemas de saúde para além de intervenções unicamente médicas. Esse cenário se modifica em 1995, com a privatização da saúde pública no município, quando foi implantado o Plano de Assistência à Saúde (PAS). O PAS, um modelo essencialmente assistencial, se desresponsabiliza pelas ações coletivas em saúde e se incompatibiliza com os princípios do SUS (Lopes, 1999). Com a reintegração da saúde ao SUS, em 2001, a Atenção Básica (especialmente o PSF) assume papel importante na organização dos serviços em saúde mental no município.

A organização da atenção à saúde mental deve seguir os ditames da promoção, da prevenção, do tratamento e da reabilitação. As ações de promoção incluem: favorecer a melhora dos relacionamentos pessoais (incluindo suas contradições); destacar as capacidades de indivíduos e comunidades; diminuir problemas relacionados ao estresse no local de trabalho; promover a noção de identidade social da comunidade; propiciar a integração e o apoio a grupos sociais; sensibilizar a população para o tema da saúde mental (Brasil, 2003).

A proposta geral de políticas em saúde mental do município de São Paulo (São Paulo, 2005) refere-se à prevenção nas escolas em um único momento, citando a necessidade da educação preventiva em álcool e drogas, que deve ser incluída progressivamente no currículo e tratada por indivíduos que tenham um bom vínculo com os alunos. Excluindo-se os tópicos a respeito de álcool e drogas, não é citado qualquer outro tipo de ação nas escolas que vise à promoção da saúde mental de crianças e adolescentes. 
Ainda de acordo com o documento, a política de saúde mental no município deve respeitar as peculiaridades de cada ciclo de vida, e devem ser reconhecidos na Atenção Básica os fatores de risco para transtornos mentais compatíveis com cada um dos ciclos. É interessante notar que, no ciclo de vida da criança, os problemas decorrentes do processo de escolarização - a queixa escolar, que é atualmente uma das mais recorrentes causas de encaminhamento para atendimento em saúde mental nas UBSs -, não constam como fator de risco na infância.

\section{A evasão e a repetência escolares}

Segundo Patto (1990), durante a década de 1930, estatísticas já revelavam altos índices de evasão e de reprovação escolares entre as classes populares. Tais índices se mantiveram por várias décadas, num estado de cronificação. Barreto (1984, citado por Patto, 1990) registra que, ao final da década de 1970, a taxa de escolarização da população de 7 a 14 anos foi de $67,4 \%$, isto é, cerca de 7.100 .000 crianças permaneceram excluídas da vida escolar nesse período, sendo que o aumento no número de vagas apenas acompanhou o crescimento vegetativo em algumas regiões. Embora, na década de 1980, tenha havido aumento do número de vagas nas escolas, garantindo acesso a grande parte da população, a qualidade do ensino oferecido não foi capaz de reverter o quadro de altas taxas de repetência e evasão.

Em 1986, dados da Fundação SEADE (1989, citados por Souza, 1997) indicavam que a maioria dos casos de reprovação e evasão escolares era de alunos provenientes das escolas públicas estaduais e municipais. Os índices de reprovação na segunda série do ensino fundamental I eram de $30,45 \%$, nas escolas públicas, contra $7,59 \%$ nas escolas particulares. Dados divulgados por Ribeiro (1992, citado por Souza, 1997) confirmam o estado de cronificação do problema, pois relatam que o aluno brasileiro permanecia, em média, oito anos e meio na escola, mas apenas 3\% dos ingressantes concluíam o ensino fundamental sem repetência.

Para Ferraro (2004), existem dois tipos de exclusão. A primeira, que o autor denomina exclusão da escola, envolve as questões da dificuldade no acesso à escola. Já a segunda forma, denominada exclusão na escola, relaciona-se aos dados de reprovação. Dados do IBGE (1996, citado por Ferraro, 2004) indicam que um total de 8,6 milhões de crianças e adolescentes com idade entre cinco e 17 anos não freqüentavam a escola à época da pesquisa. O número de crianças excluídas do sistema educacional diminuiu progressivamente dos sete anos, com 10,8\%, até os 11 anos de idade, com 7,1\% . A partir dos 12 anos, essa taxa de nãofreqüência passa a aumentar, chegando a $42,8 \%$ de adolescentes com 17 anos excluídos da escola. 
Os números de exclusão na escola, que são os alunos reprovados mais de duas vezes, atingem seu ápice com a taxa de $45,9 \%$ de adolescentes aos 14 anos de idade com defasagem na relação idadesérie. Dos alunos com 11 e 12 anos, respectivamente $36,9 \%$ e 40,5\%, foram reprovados mais de duas vezes, o que demonstra que as taxas de exclusão na escola aumentam de acordo com a idade (IBGE, 1996, citado por Ferraro, 2004).

Com o intuito de reverter esse quadro, sob a perspectiva de que a prática da reprovação é punitiva e seletiva, têm sido realizadas algumas tentativas de enfrentamento dos problemas da escolarização inadequa$\mathrm{da}$, com mudanças na política educacional que procuram superar o modelo tradicional de promoção de uma série para a seguinte. A proposta principal é a organização do ensino em ciclos, que traz consigo o princípio da progressão continuada. O ciclo não só se propõe reduzir os índices de reprovação, como também visa a uma organização curricular e didática que seja adequada aos estágios de desenvolvimento da criança e do adolescente, com intervalos elásticos em que se podem desenvolver métodos mais eficazes para apreensão de conteúdos educacionais, respeitando o desenvolvimento cognitivo, social e afetivo do aluno (Paro, 2001). Contudo, o que se observa na prática é que tais princípios não são aplicados, nem são dadas efetivamente opções diferentes aos alunos, o que redunda num grande número de repetências ao final do ciclo.

Para Souza (1997), a repetência não tem o efeito desejado de possibilitar que a criança "refaça" o aprendizado, mas, ao contrário, cria espaço para a estigmatização, marcando o aluno como diferente ou deficiente em relação aos demais. A autora ainda alude ao fato de que, nos psicodiagnósticos realizados pelos psicólogos em crianças com inadaptações escolares, muitas vezes não há qualquer referência ao papel exercido pela escola ou a estratégias utilizadas pelo professor para reverter o quadro da dificuldade. Há casos em que o laudo psicológico é taxativo, colaborando em muito para o reforço de estigmatizações já sofridas pela criança repetente no ambiente escolar.

Queixa escolar: atuação do psicólogo e interfaces com a educação

Tendo em vista tais considerações preliminares, propusemo-nos realizar, na tentativa de verificar o estado atual da demanda e do atendimento de crianças em Unidades Básicas de Saúde (UBSs), um levantamento dos atendimentos efetuados por psicólogos nas UBSs da zona norte da cidade de São Paulo, nos moldes do trabalho realizado em 1993 por Bueno et al. (2001) na zona sul do mesmo município. 
Pretendemos com esse trabalho averiguar se as recentes políticas educacionais e de saúde e se os estudos a respeito da demanda escolar em clínicas-escola e serviços públicos de saúde têm surtido efeito e provocado mudanças significativas na prática dos psicólogos das UBSs, e estimular a reflexão sobre um problema que envolve duas áreas importantes para o desenvolvimento social: educação e saúde.

Consultando 104 prontuários de crianças de seis anos a 12 anos e 11 meses de idade que demandaram, no segundo trimestre do ano de 2005, a área de saúde mental de sete Unidades Básicas de Saúde da zona norte do município de São Paulo, fizemos constatações que relatamos resumidamente nos parágrafos a seguir.

Com base em Bueno et al. (2001), as queixas apresentadas foram categorizadas como: dificuldade de aprendizagem, problemas de comportamento relacionado à escola e queixas não relacionadas à escola. As queixas classificadas como dificuldades de aprendizagem foram aquelas descritas nos prontuários como"dificuldade escolar, dificuldade de aprendizagem, déficit de aprendizagem, atraso escolar, baixo rendimento escolar, não sabe ler, não sabe escrever, não vai bem na escola, não reconhece as letras, dificuldade de atenção e concentração, agitação, inquietude e hiperatividade durante as aulas".Alguns dos problemas de comportamento relacionados à escola foram registrados pelos psicólogos como "não obedece a ninguém, é agressivo na escola, chora quando chamado para atividades, apresenta distúrbio de comportamento na escola, desorganização e bagunça". Já as queixas não relacionadas à escola foram, por exemplo,"chora muito, sofre maus tratos, é depressiva, muito nervosa, insegura, revela problemas emocionais, apresenta mudanças de comportamento, enurese, baixo peso". Consideramos queixas escolares todas aquelas que incluíam questões relacionadas à escola, fossem elas de ordem pedagógica ou comportamental.

O estudo revelou que a maioria das crianças atendidas no serviço de saúde mental das UBSs era do sexo masculino (70,2\%), tinha entre oito e dez anos de idade (média de 9,2 anos) e apresentava queixas escolares $(76,9 \%)$, tanto aquelas relacionadas a dificuldades de aprendizagem (53,8\%), quanto as que diziam respeito a problemas de comportamento na escola. Esses dados são compatíveis com os encontrados em outras pesquisas.

Silva (1994) verificou que $59 \%$ do total dos casos atendidos em serviços públicos de saúde mental no município de Ribeirão Preto eram de crianças na faixa etária de sete a 12 anos, sendo $43,5 \%$ do sexo masculino. Santos (1990), na caracterização da clientela de uma clínica psicológica da prefeitura de São Paulo, constatou que $67,7 \%$ das crianças atendidas eram do sexo masculino. Silvares (1989, citada por Souza, 1997) também verificou em análise de prontuários da clínica-escola do Instituto de Psicologia da USP que as queixas mais freqüentes eram por mau desempenho escolar, seguidas de comportamento agressivo; a maioria se refe- 
ria a crianças do sexo masculino (71\%) e que freqüentavam entre a $1^{\mathrm{a}}$ e a $4^{\text {a }}$ séries do primeiro grau. A autora concluiu que os meninos foram encaminhados por motivos diferentes daqueles das meninas: enquanto as queixas relativas a meninas eram comportamentos não-explícitos, os meninos tinham como queixa predominante distúrbios do desenvolvimento e dificuldades escolares.

Souza (2002) constatou que a média de idade dos encaminhados a uma clínica-escola da cidade de São Paulo era de 9,3 anos, que aproximadamente sete em cada dez crianças encaminhadas para a clínica eram meninos e que as meninas tinham, como motivo do encaminhamento, menos atitudes consideradas indesejáveis do que os meninos. $O$ estudo indicou ainda que $66 \%$ das crianças estavam entre a $1^{\text {a }}$ e a $3^{\text {a }}$ séries, com $35 \%$ das crianças atendidas na $2^{\text {a }}$ série.

Bueno et al. (2001), em pesquisa realizada em UBSs da região sul do município de São Paulo, verificaram que $65 \%$ dos casos de crianças atendidas na faixa etária entre sete e 12 anos tinham alguma queixa relacionada à escola. Destes, $27,9 \%$ dos clientes estavam com idade entre nove e dez anos, e a maioria cursava a $2^{\text {a }}$ série. Mais de $50 \%$ dos casos encaminhados nessa faixa etária eram de meninos (63\%).

Segundo Morais e Souza (2001), talvez os meninos sejam encaminhados mais freqüentemente em função de razões socioculturais. Por serem mais ativos, indisciplinados e agitados, sua conduta - que contrasta com a conduta aparentemente mais disciplinada das meninas - seria menos aceita pelos professores. Lopes (1983, citado por Silva, 1994) sugere que, talvez, o fracasso escolar das crianças do sexo feminino seja assimilado como algo de menor importância em relação ao de crianças do sexo masculino. Santos (1990) levanta a hipótese de que existiria maior expectativa quanto à aquisição de habilidades sociais e cognitivas em relação aos meninos, enquanto os comportamentos que se esperam das meninas é que sejam mais caseiras, obedientes e estudiosas.

De acordo com Souza (1997), as explicações para a tendência a ser maior o número de meninos encaminhados para atendimentos psicológicos vão desde a diferença de perfis comportamentais entre meninos e meninas até aquelas que enfatizam a somatória de fatores envolvendo as condições do ensino escolar e o tipo de comportamento exigido pela escola. Nota-se na escola o medo de que esse menino (aluno) venha a ser um futuro marginal, passando-se a exigir dele uma série de habilidades e comportamentos considerados garantia de submissão (pp. 26-27).

As pesquisas anteriormente citadas apontam para o fato de que grande parte das crianças atendidas freqüentava a $2^{\text {a }}$ série. Os resultados de nosso estudo apresentam uma realidade algo diferente, pois a maior parte das queixas escolares foi de crianças que freqüentavam a $4^{\text {a }}$ série, muito embora as queixas escolares tenham preponderado sobre as demais nas crianças que freqüentavam de $1^{\text {a }}$ a $5^{\text {a }}$ séries. 
Morais e Souza (2001) concluíram em seu estudo que havia um número significativo de crianças da $2^{\text {a }}$ série encaminhadas para atendimento, pois essa série, à época da pesquisa, coincidia com o final do ciclo básico, que era de dois anos ( $1^{\text {a }}$ e $2^{\text {a }}$ séries). Atualmente, os ciclos das escolas fundamentais, tanto municipais quanto estaduais, são divididos em um inicial, da $1^{\mathrm{a}}$ à $4^{\mathrm{a}}$ série, e um segundo, da $5^{\mathrm{a}}$ a $8^{\mathrm{a}}$ série, sendo que, dentro do período dos ciclos, há o regime de progressão continuada.

Talvez o regime de progressão continuada tenha possibilitado que a maior parte das crianças cujo protocolo foi investigado neste estudo estivesse na série esperada de acordo com a idade. No entanto, quando chegavam à $4^{a}$ série, já no início do ano (período em que foi realizada a pesquisa), grande parte das crianças era encaminhada para os serviços de saúde mental principalmente por queixas de dificuldade de aprendizagem associadas a problemas de comportamento na escola, no momento do ciclo em que a criança pode repetir o ano.

É provável que os problemas de comportamento relacionados à escola apareçam associados a dificuldades de aprendizagem em decorrência de um sistema de ensino que não lida satisfatoriamente com a criança que não aprende, nem procura sanar suas dificuldades com atividades complementares e mais diversificadas, o que pode gerar no aluno sentimentos de inadequação e estigmatizar a "criança que não aprende", originando problemas adicionais de comportamento no ambiente escolar.

Segundo Gomes (2004), a implantação do regime de progressão continuada exige a adesão dos professores e "uma formação continuada eficaz, junto à escola e não em programas de massa, além de jornada ampliada" (p. 40). O autor coloca ainda que o regime de progressão continuada é muitas vezes entendido pelos professores como uma aprovação automática, o que modifica o sistema de controle de aprendizagem e de comportamento na sala de aula, antes baseado na sanção da reprovação. Dessa forma, os professores "conseguem não raro cumprir formalmente a legislação e as normas sem modificar a avaliação e suas representações, empurrando a reprovação para o fim do ciclo básico ou, ainda, abandonando o aluno com baixo aproveitamento e desresponsabilizando-se por ele" (p. 45).

Santos (1990) constatou que na $1^{\text {a }}$ série ocorreu o maior número de queixas referentes a "distúrbios de aprendizagem" (28\%), aparecendo ainda alta incidência de queixas de "nervosismo" (14\%). É importante destacar que, no presente estudo, $43 \%$ de crianças com seis anos de idade freqüentavam a $1^{\text {a }}$ série. Muitas dessas crianças procuraram atendimento por problemas de comportamento relacionados à escola associados a queixas não relacionadas à escola.É surpreendente que os alunos tenham sido encaminhados para atendimento no início da escolarização, mes- 
mo sendo esse período reconhecido como natural de adaptação. Segundo Souza (1997), "o encaminhamento de crianças que se encontram no início do processo de alfabetização pode caracterizar a existência de um conjunto de expectativas escolares em relação ao aluno ingressante. Assim, qualquer aluno que se desvie do padrão estabelecido pela escola passa a ser visto como um problema potencial" (p. 25).

Em relação ao caráter da escola,em pesquisa realizada por Souza (2002) em clínica-escola do município de São Paulo, a grande maioria dos encaminhamentos era proveniente de escolas públicas, com uma parcela muito pequena de alunos de escolas privadas. Bueno et al. (2001) constataram que a maior parte dos usuários atendidos em UBSs da zona sul da cidade de São Paulo pertencia a escolas públicas (82\%), havendo número equivalente de alunos atendidos provenientes de escolas municipais e estaduais.

Nossos resultados sugerem que os encaminhamentos para atendimentos psicológicos nas UBSs continuam sendo predominantemente realizados pelas escolas públicas, não havendo diferença significativa entre as escolas estaduais e municipais. Tal resultado é esperado, tendo em vista que a maioria da população SUS dependente utiliza também o sistema público de educação.

Quanto à origem dos encaminhamentos, Carvalho e Térzis (1989) constataram, em levantamento realizado numa clínica-escola, que mais da metade dos clientes foram encaminhados à clínica por instituições educacionais. Bueno et al. (2001) verificaram que a escola era a principal fonte de encaminhamentos às UBSs de crianças de até 12 anos de idade, excetuando-se a faixa dos sete e oito anos, em que era mais freqüente o encaminhamento por parte de outros profissionais. Pesquisa realizada por Silva (1994), no serviço público de saúde do município de Ribeirão Preto, revelou que, na faixa etária entre sete e 12 anos, as crianças eram encaminhadas ou de forma direta pela escola ou indireta por meio de outros profissionais.

Em concordância com tais estudos, a maior parte dos encaminhamentos realizados às UBSs da zona norte do município de São Paulo foram de origem escolar, seguidos por encaminhamentos realizados pela família e pelo médico. Além disso, $51,9 \%$ das queixas escolares foram provenientes de encaminhamentos realizados pela escola.

Como comentamos anteriormente, uma possível causa para o grande número de encaminhamentos realizados pelas escolas seria a expectativa dos professores de encontrarem apenas alunos ideais em sala de aula, sendo que qualquer desvio dessa concepção preestabelecida sobre o comportamento esperado é visto como motivo para atendimento psicológico (Souza, 2002). 
Segundo Silva (1994), a escola psicologiza o fracasso escolar quando atribui aos desajustes escolares a classificação de problemas de aprendizagem, admitindo como causa dos problemas aspectos intrapsíquicos e/ ou orgânicos da criança e, como resolução da não adaptação escolar, o encaminhamento aos psicólogos. A autora diz, ainda, que o erro ocorre quando se assumem os problemas escolares como distúrbios que jamais incidiriam na população na mesma freqüência em que as escolas os "diagnosticam". Boarini (1996) afirma que, "se confirmada a psicopatologia das crianças que são encaminhadas às UBSs, o problema deixa de ser específico da área da saúde para ser um problema federal ou de toda a população brasileira" (p. 121).

Collares e Moysés (1997) fazem uma crítica à crença que alguns profissionais da educação têm em relação ao poder de resolução dos profissionais da saúde. Segundo as autoras, acredita-se nas escolas que as crianças não aprendem por serem portadoras de doenças orgânicas ou emocionais e que, por esse motivo, devem ser encaminhadas aos serviços de saúde. Dessa forma, atribuem-se a fenômenos sociais modelos biológicos, desconsiderando os fatores educacionais, culturais e econômicos envolvidos no processo de escolarização. As autoras afirmam ainda que:

os profissionais da educação em geral acreditam em sua capacidade de identificar facilmente as crianças com possíveis problemas de saúde, crêem em seu próprio tirocínio diagnóstico... atribuem o não-aprender na escola a problemas de saúde, atribuem aos profissionais da saúde uma competência quase mágica, com possibilidades de atuação infinitas. (Collares \& Moysés, 1997, pp. 142-143)

Em relação às queixas, pesquisa realizada por Souza (2002) em clínicas-escolas de cursos de graduação em Psicologia demonstra que $26 \%$ dos encaminhamentos eram por problemas de aprendizagem atrelados a problemas de atitude em sala de aula, $24 \%$ por problemas de aprendizagem apenas e $19 \%$ por problemas de atitude na escola, somando $69 \%$ de crianças com problemas de aprendizagem ou com atitudes consideradas inadequadas na escola. Segundo Bueno et al.(2001), as queixas por problemas relacionados à escola em Unidades Básicas de Saúde totalizavam $64,8 \%$ dos casos.

Santos (1990) teve como resultado em estudo em clínica psicológica de São Paulo que a maior parte das queixas apresentadas eram relacionadas a "distúrbios de aprendizagem" e, como segunda maior porcentagem, apareceram queixas relativas a "nervosismo". Silvares (1989, citada por Souza, 1997), analisando os prontuários de todos os atendimentos em uma clínica-escola, entre 1983 e 1989, obteve como queixa mais freqüente o mau desempenho escolar (41\%) e, em seguida, comportamento agressivo ou de brigas (28\%) e dificuldades de fala 
(25\%). Silva (1994) observou nos serviços públicos de saúde em Ribeirão Preto que, na faixa etária na qual se concentrou o maior número de solicitações de atendimento (7-12 anos), existiam $71,4 \%$ de queixas de aprendizagem, todas ligadas ao problema de desajuste escolar.

Em nosso estudo, verificamos que $24 \%$ das queixas apresentadas não eram relacionadas à escola, enquanto $20,2 \%$ eram por dificuldade de aprendizagem/atraso escolar e $16,3 \%$ por problemas de comportamento relacionados à escola. $O$ total de queixas por dificuldade de aprendizagem foi, então, de 53,8\%, somando-as quando aparecem associadas a queixas de outra ordem. Já o total de queixas escolares alcançou 76,9\%. Esse quadro mostra que, apesar dos esforços de alguns psicólogos e estudiosos da psicologia escolar, as escolas continuam tendendo a psicologizar ou a biologizar as queixas escolares, em vez de reformular suas práticas e rever as questões da instituição educacional.

Encontramos que as queixas associadas a dificuldades de aprendizagem/atraso escolar foram dificuldades de concentração/atenção $(18,7 \%)$, agitação e inquietude $(9,3 \%)$ e hiperatividade ( $8 \%)$. Tais queixas estão relacionadas a comportamentos da criança que fogem ao que teoricamente se espera de um "bom aluno". Muito embora se saiba que as dificuldades de concentração (que podem estar relacionadas com a agitação ou a hiperatividade) efetivamente prejudicam o desempenho escolar, as causas desse fenômeno podem ser tanto problemas emocionais (que "desviam" a atenção da criança) quanto questões culturais, tendo em vista que as crianças das camadas mais pobres da população são educadas de forma a ter respostas rápidas e práticas a problemas do cotidiano. O fato é que os professores não estão preparados para lidar com o aluno inquieto/agitado/hiperativo, uma vez que consideram esse comportamento perturbador dos processos tradicionais de sala de aula. A esse respeito, é interessante observar a solução encontrada pela professora Leila Soueid, em relato de experiência em que criou alternativas ao modelo "quadro-negro, caderno, livro", montando diversas atividades de participação grupal dos alunos, valorizando os aspectos positivos de alunos com "problemas de comportamento" (Soueid, Minto, \& Morais, 2001).

A maior parte das queixas por problemas de comportamento relacionados à escola foi por agressividade/nervosismo (35,5\%) e dificuldade de socialização (17,8\%). Segundo análise de Souza (2002) a respeito das queixas não relacionadas a problemas de aprendizagem, é provável que exista um conjunto de regras e atitudes esperadas, que seriam as únicas consideradas adequadas dentro da escola. A respeito das queixas por problemas de agressividade/nervosismo ou por dificuldade de socialização, a autora afirma que, no encaminhamento, muitas vezes não é considerado o contexto em que ocorre nem a dinâmica das relações responsáveis pelo desencadear do comportamento dito inadequado. Dessa forma, a criança e sua estrutura de personalidade 
são consideradas responsáveis pelo desajuste, pelo comportamento tímido ou agressivo em demasia, merecendo tratamento para que retorne ao eixo de normalidade.

Com respeito à conduta adotada pelos psicólogos, no trabalho de Bueno et al. (2001), os resultados apontaram que, dentre as condutas adotadas pelos profissionais de saúde, predominaram a orientação famili$\operatorname{ar}(23,2 \%)$, o psicodiagnóstico (18,4\%) e as terapias individual e em grupo (ambas com 13,5\%). As autoras constataram que a conduta adotada pelos profissionais de saúde mental era a mesma, independentemente de a queixa ser ou não ligada à escola.

Em nosso trabalho, constatou-se que a conduta mais freqüentemente adotada pelos profissionais de psicologia participantes da pesquisa foi a orientação familiar. Percebe-se que, independentemente do teor da queixa, os procedimentos mais utilizados pelos psicólogos são os tradicionais: orientação familiar (24,7\%), terapia individual (15,3\%) e grupal (20,5\%), sendo que, em casos de queixa não escolar, a conduta adotada com maior freqüência foi a terapia individual. Em apenas $1 \%$ dos casos que procuraram a UBS com queixa escolar foi realizada entrevista com professor. Tais resultados indicam que, em grande parte dos casos, os profissionais encaram as queixas escolares como passíveis de tratamento clínico, o que implica a utilização de uma concepção médica, biologizante, de causa e efeito entre problemas emocionais e dificuldades de aprendizagem. Segundo Collares e Moysés (1997), "a demanda por serviços, mesmo quando aparenta ser espontânea, é conformada pelo próprio serviço, que define, a priori, seus critérios de inclusão/exclusão, isto é, suas prioridades" (p. 151).

O psicólogo, muitas vezes, desconhece a complexa rede de relações imbricadas na manifestação da queixa escolar, deixando à margem determinações sociais e institucionais que influenciam na produção das dificuldades escolares. "O fracasso escolar constitui problema institucional, político e pedagógico, que só pode ser efetivamente enfrentado, superado, por mudanças institucionais nos campos político e pedagógico. Medidas individuais, centradas na criança, são incapazes de atingir os objetivos a que se propõem" (Collares \& Moysés, 1997, p. 155).

Souza (2004) questiona a possibilidade de as crianças integrarem ou instrumentalizarem os aspectos vivenciados em terapia se convivem por 30 horas semanais com situações ameaçadoras, freqüentemente presentes na realidade escolar. Os psicólogos muitas vezes não têm a formação adequada para buscar outras formas de atendimento à queixa escolar além do atendimento individual das crianças e de sua família, excluindo, dessa forma, o papel da instituição escolar na produção e solução das dificuldades. 
Para Dimenstein (2000), os currículos de psicologia reproduzem o modelo clínico liberal privatista, modelo da psicoterapia individual com embasamento psicanalítico, valorizado em demasia, o que se constitui num entrave para o exercício profissional em novas áreas, que exigem uma atuação diferenciada do que foi vivenciado na formação, como no atendimento à queixa escolar em serviços de assistência pública à saúde.

Segundo Collares e Moysés (1997), os profissionais da saúde e educação têm uma formação profissional acrítica, a-histórica, que encara os problemas de saúde como barreira para aprendizagem, desconsiderando determinantes sociais das dificuldades escolares tais como condições de vida, inserção familiar nos estratos sociais, nos meios de produção."Tudo é reduzido ao plano da natureza, das ciências naturais, tudo é passível das mesmas formas de análise, de entendimento" (p. 149).

Freller et al. (2001) propõem uma nova forma de atendimento à queixa escolar que - diferentemente do atendimento clínico tradicional muitas vezes demorado e que foca prioritariamente os mecanismos intrapsíquicos e as relações familiares - inclui os processos e práticas escolares na solução das dificuldades. Dessa forma, são levadas em conta as relações no interior da escola, com intervenções tais como: mudar de classe, mudar de lugar na sala de aula, assumir novos papéis na relação com os colegas e professores, passar a fazer atividades extra-escolares físicas ou expressivas etc. Assim, emergem novos espaços de movimentação para a criança, que também podem funcionar como desencadeadores de uma mudança interna.

Outra constatação de nosso estudo é a falta de iniciativa dos psicólogos em trabalhar intersetorialmente, pois se verificou que os poucos encaminhamentos feitos foram a psiquiatras e fonoaudiólogos. Grande parte da solução dos problemas que se enfrentam nos serviços públicos de saúde não pode ser resolvida isoladamente. A atuação interdisciplinar e intersetorial precisa ser incorporada com urgência nos serviços públicos para a resolutividade dos problemas educacionais e de saúde, que aparecem sempre interligados com questões institucionais, socioculturais e econômicas (Dimenstein, 1998; Morais, 2004; Morais \& Souza, 2001).

A principal conclusão a que se chega, ao final deste trabalho, é que, com pequenas exceções, poucas mudanças têm havido na forma de atender aos casos de queixa escolar. A formação do psicólogo, como bem descreve Dimenstein (1998), até hoje praticamente voltada para a clínica dentro de um modelo medicocêntrico, nada fará para mudar essa realidade. Sabe-se que a representação social do psicólogo de consultório é muito mais positiva do que a daquele que atua nos serviços públicos - que parece absorver a "pobreza" dos usuários -, mas a realidade tem mostrado que um contingente cada vez maior desses profissionais atua na área de saúde pública. Portanto, é preciso mudar o modelo clínico hegemônico para dar conta da realidade da clientela atendida 
pelos sistemas públicos de saúde e de educação. Para isso, é imperiosa a revisão do currículo de formação em psicologia e, por parte dos psicólogos que já estão atuando na rede pública, é imprescindível repensar as formas de trabalho e de enfrentar os problemas em grande parte determinados pela realidade social do país.

\title{
School Complaint: Psychologists' Performance and Interfaces with Education.
}

\begin{abstract}
This paper intends to discuss the recent educational and health politics, and to examine if the studies about the scholar demand in school clinics and in public health services have engendered significant changes in psychologists' practices in primary care public health units. An analysis of dossiers of children who attended, in the second semester of 2005, the area of mental health in primary care units showed that school complaint represented a significant percentage of cases, indicating a tendency in schools towards considering that adjustment difficulties are caused by factors focused in the children and their family, in prejudice of implications of educational, socio-cultural, and economic issues. The study also revealed that the conduct adopted by psychologists, based on a traditional clinical model, tends to reassure this belief, excluding the role of the educational institution in the production and solution of the presented difficulties. We claim that public health psychologists need to review their practice in order to find new forms of facing school complaints, considering all the factors involved in them.
\end{abstract}

Keywords: School ajustment. Mental health services. Psychologist performance.

\section{Plainte scolaire: performance du psychologue et interfaces avec l'éducation.}

Résumé: On discute ici les récentes politiques de l'éducation et de la santé en vérifiant si les études concernant la plainte scolaire auprès des cliniques-écoles et des services publics de santé ont provoqué des changements chez les Unités Basiques de Santé (UBSs). Une analyse des dossiers des enfants qui ont visité, au second trimestre de 2005 , le secteur de santé mentale d'UBSs de la région Nord de la ville de São Paulo a révélé que la plainte scolaire est significative et que les pratiques en vigueur ont une tendance à considérer que les difficultés d'ajustement scolaire sont causées par des troubles chez l'enfant et sa famille, sans l'implication des questions scolaires, socioculturelles ou économiques. On peut vérifier que la conduite adoptée par des psychologues, calquée sur une clinique traditionnel, tend à réaffirmer l'exclusion de l'institution scolaire. Cela dit, on propose de repenser leurs pratiques professionnels en cherchant de nouvelles formes d'envisager la plainte scolaire, tous les facteurs impliqués.

Mots-clés: Ajustement scolaire. Service de santé mentale.Performance du psychologue. 
Queja escolar: actuación del psicólogo e interfaces con la educación.

Resumen: Pretendemos con este trabajo discutir si las recientes políticas educacionales y de salud y si los estudios sobre la demanda escolar en clínicas-escuelas y servicios públicos de salud han surtido efecto y provocado cambios significativos en la práctica de los psicólogos de las UBSs. Consultando 104 prontuarios de niños que demandaron, en el segundo trimestre de 2005, el área de salud mental de siete UBSs de la región norte de la ciudad de São Paulo, se verifica que la queja escolar surge en porcentaje significativo en las UBSs, indicando una tendencia a considerar que las dificultades de ajuste a la escuela son causadas por factores centrados en el niño y en su familia, en detrimento de la implicación de cuestiones educacionales, culturales y económicas. Se verificó que la mayoría de los psicólogos no tiene formación adecuada para buscar otras formas de atención, excluyendo el papel de la institución escolar en la producción y solución de las dificultades. Se propone una revisión del currículo de los cursos de formación en psicología y un repensar de las prácticas de los profesionales que actúan en la red pública de salud y educación en el sentido de buscar nuevas maneras de atender la queja escolar, teniendo en cuenta todos los factores en ella implicados.

Palabras-clave: Adaptación escolar.Servicios de salud mental. Actuación del psicólogo.

\section{Referências}

Boarini, M. L. (1996). A formação (necessária) do psicólogo para atuar na Saúde Pública. Psicologia em Estudo, 1, 93-132.

Brasil. Ministério da Saúde. (2003). Saúde mental e atenção básica: o vínculo e o diálogo necessários. Brasília, DF.

Bueno, M. T. B., Morais, M. L. S., \& Urbinatti, A. M. I. (2001). Queixa escolar: proposta de um modelo de intervenção. In M.L.S. Morais \& B.P.Souza (Eds.), Saúde e educação: muito prazer! Novos rumos no atendimento à queixa escolar (pp. 51-68). São Paulo: Casa do Psicólogo.

Carvalho, R. M. L. L., \& Térzis, A. (1989). Caracterização da clientela atendida na clínica psicológica do instituto de psicologia da PUCCAMP - II. Estudos de Psicologia, 1, 94-110.

Collares, C. A. L., \& Moysés, M. A. A. (1986). Educação ou Saúde? Educação X Saúde? Educação e Saúde! Cadernos CEDES, 15, 7-16.

Collares, C. A. L., \& Moysés, M. A. A. (1997). O profissional de saúde e o fracasso escolar. In Conselho Regional de Psicologia de São Paulo, Educação especial em debate (pp. 137-159). São Paulo: Casa do Psicólogo.

Dimenstein, M. (1998).O psicólogo nas Unidades Básicas de Saúde: desafios para a formação e atuação profissionais. Estudos de Psicologia (Natal), 3, 53-81. 
Dimenstein, M. (2000). A cultura profissional do psicólogo e o ideário individualista: implicações para a prática no campo da assistência pública a saúde. Estudos em Psicologia, 5, 95-121.

Ferraro, A. R. (2004). Escolarização no Brasil na ótica da exclusão. In A. Marchesi \& C. H. Gil (Eds.), Fracasso escolar: uma perspectiva multicultural (pp. 48-65). Porto Alegre: Artmed.

Freller, C.C., Souza, B.P, Angelucci, C.B., Bonadio, A. N., Dias, A.C, Lins, F. R.S., \& Macedo, T. E. R. (2001). Orientação à queixa escolar. Psicologia em Estudo, 2, 129-134.

Gomes, C. A. (2004). Quinze anos de ciclos no ensino fundamental: um balanço das pesquisas sobre sua implantação. Revista. Brasileira de Educação, 25, 39-52. Recuperado em fevereiro de 2007, da SciELO (Scientific Electronic Library OnLine): http://www.scielo.br

Lopes, I. C. (1999). A contribuição paulistana à reforma em saúde mental brasileira. In M. C. T. Vieira \& M. C. G. Vincentim (Eds.), Tecendo a rede: trajetórias da saúde mental em São Paulo 1989-1996 (pp. 42-64). Taubaté, SP: Cabral.

Morais, M.L.S., \& Souza, B.P. (2001). Saúde e educação: muito prazer! Novos rumos no atendimento à queixa escolar. São Paulo: Casa do Psicólogo.

Morais, M.L.S.(2004). Redes de proteção e de inclusão social:a importância da atuação intersetorial na atenção à saúde. Boletim do Instituto de Saúde, 34, 21-21.

Nutti, J.Z. (2000). Concepções sobre as possibilidades de integração entre Saúde e Educação: um estudo de caso. Psicopedagogia on line. Recuperado em fevereiro de 2006, de http://www.psicopedagogia.com.br

Paro, V.H.(2001). Reprovação escolar renúncia à educação. São Paulo:Xamã.

Patto, M. H. S. (1990). A produção do fracasso escolar: histórias de submissão e rebeldia. São Paulo:T. A. Queiroz.

Santos, M. A. (1990). Caracterização da clientela de uma clínica psicológica da Prefeitura de São Paulo. Arquivos Brasileiros de Psicologia, 42, 79-94.

São Paulo (Município). Secretaria Municipal de Saúde. (2005). Saúde mental geral. Recuperado em fevereiro de 2006, de http:// www.prefeitura. sp.gov.br/secretarias/saúde

Silva, R. C. (1994). O fracasso escolar: a quem atribuir? Paidéia, 7, 33-41.

Soueid, L., Minto, E. W., \& Morais, M. L. S. (2001). Um trabalho com uma classe de crianças desacreditadas. In M.L.S. Morais \& B.P. Souza (Eds.), Saúde e educação: muito prazer! Novos rumos no atendimento à queixa escolar (pp. 51-68). São Paulo: Casa do Psicólogo. 
Souza, M. P. R. (1997). A queixa escolar e o predomínio de uma visão de mundo. In: A. M. Machado \& M.P. R. Souza (Eds.), Psicologia escolar:em busca de novos rumos (pp. 19-37) São Paulo: Casa do Psicólogo.

Souza, M. P. R. (2002). Problemas de aprendizagem ou problemas de escolarização? Repensando o cotidiano escolar à luz da perspectiva histórico-crítica em psicologia. In D. T. R. Souza, M. K. Oliveira \& T. C. Rego (Eds.), Psicologia, educação e as temáticas da vida contemporânea (pp. 177-195). São Paulo: Moderna. 